\title{
Does the fibrinogen/albumin ratio predict the prognosis of pregnancies with abortus imminens?
}

\author{
Ceyda S. Usta, MD, Tugba K. Atik, MD, Ruhsen Ozcaglayan, MD, Cagla B. Bulbul, MD, \\ Figen E. Camili, $M D$, Ertan Adali, $M D$.
}

\begin{abstract}
الأهداف : دراسة نسبة الفيبرينوجين/الألبومين (FAR) للنساء الحوامل

المابات بالإجهاض الوشيك (AI ) وقيمته التنبؤية للتنبؤ بالإجهاض لنورل التلقائي.

المنهجية : شخصنا 102 حالة حمل مبكر، ومن بينها 52 حالة تم تشخيصها

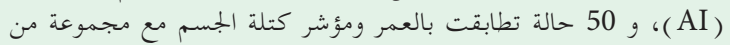

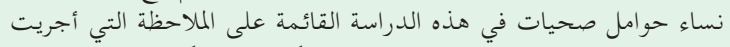

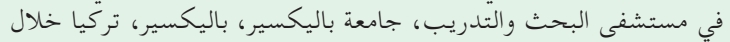

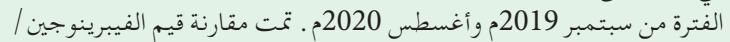
الألبومين بين مجموعة AI ومجموعة التحكم.

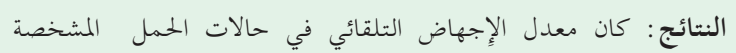

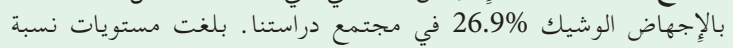

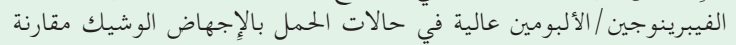

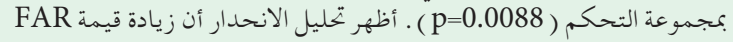

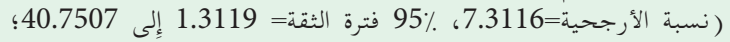

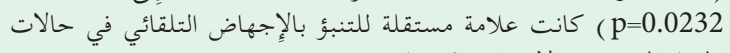
الحمل المشخصة بالإجهاض الوشيك.

الحلاصة : زادت حالات حمل الإجهاض الوشيك من مستويات FAR مقارنة

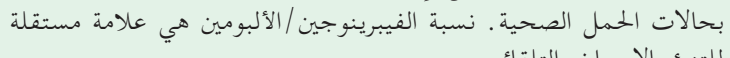

Objectives: To investigate the fibrinogen/albumin ratio (FAR) of pregnant women with abortus imminens (AI) and its prognostic value for predicting spontaneous abortion.

Methods: A total 102 early pregnancies, 52 had been diagnosed with $\mathrm{AI}$ and 50 ages and body mass index matched healthy control pregnant women were included in this prospective observational study conducted in the Research and Training Hospital, Balikesir University, Balikesir, Turkey between September 2019 and August 2020. Fibrinogen/ albumin values were compared between AI and control group.

Results: The rate of spontaneous abortion in AI pregnancies was $26.9 \%$ in our study population.
Fibrinogen/albumin ratio levels were higher in AI pregnancies than in controls $(p=0.0088)$. The regression analysis have shown that the increased FAR value (odds ratio [OR]: 7.3116 [95\% CI: 1.3119 to 40.7507]; $p=0.0232$ ) was an independent marker for spontaneous abortion prediction in AI pregnancies.

Conclusion: Pregnancies with AI have increased levels of FAR compared to healthy pregnancies. Fibrinogen/ albumin ratio is an independent marker for predicting spontaneous abortion.

Keywords: fibrinogen to albumin ratio, abortus imminens, inflammation, spontaneous abortion

Saudi Med J 2021; Vol. 42 (3): 255-263 doi: 10.15537/smj.2021.42.3.20200695

From the Department of Obstetrics and Gynecology (Usta, Bulbul, Camili), from the Department of Clinical Microbiology (Atik), and from the Department of Internal Medicine (Ozcaglayan), School of Medicine, Balikesir University, Balikesir, Turkey.

Received 2nd November 2020. Accepted 20th January 2021.

Address correspondence and reprint request to: Dr. Ceyda S. Usta, Department of Obstetrics and Gynecology, School of Medicine, Balikesir University, Balikesir,Turkey.E-mail: drceydausta@gmail.com ORCID ID: https://orcid.org/0000-0002-3223-7729

A bortus imminens (AI) is defined as the presence of vaginal spotting or bleeding without cervical dilatation and/or effacement before the 20th week of pregnancy. It frequently occurs during the first 12 weeks of pregnancy. Abortus imminens affects approximately $20-50 \%$ of all pregnancies ${ }^{1}$ and it may cause abdominal cramps or pelvic pain. Recent studies clearly demonstrated that there is an increased risk of adverse pregnancy outcomes such as preterm delivery, low birth weight, and perinatal death in AI pregnancies. $^{2}$ Abortus imminens is also associated with 
spontaneous abortion in subsequent gestational weeks. ${ }^{3}$ Despite its clinical importance, the pathophysiology of $\mathrm{AI}$ is still not known. Previous studies have suggested that adequate invasion of cytotrophoblasts into the endometrial and myometrial layer and their sufficient transformation into the spiral arteries in the first trimester of the gestation are main stone for healthy embryonic development. Actually, failure of trophoblast invasion into the endometrium and spiral arteries may decrease placental blood flow at subsequent gestational weeks. This condition eventually lead to placental insufficiency and oxidative stress. ${ }^{4}$ Placental ischemia and oxidative stress cause inflammatory responses and cell activation in vascular endothelium, which lead the development of pregnancy complications including spontaneous abortion, preeclampsia, and intrauterine growth restriction (IUGR).,5

Fibrinogen (factor 1) is a glycoprotein synthesized by liver cells and is one of the 13 coagulation factors responsible for normal blood clotting. It is also a positive acute phase response protein produced in response to proinflammatory cytokines. ${ }^{6}$ Circulating levels of fibrinogen is characterized by elevation in systemic inflammatory condition. Fibrinogen also increases during pregnancy. ${ }^{7}$ Physiologically, procoagulant levels, including that of fibrinogen increase and anti-coagulant levels decrease in the blood during pregnancy; the coagulation system is, overall, strong in pregnant women. ${ }^{7}$ However, excessive increases in fibrinogen levels heighten the risk of thromboembolism, which causes placental infarction and may lead to miscarriage.

Albumin, produced by the liver, is a member of blood transport protein family. It is also considered a negative acute phase protein. ${ }^{8}$ Reduced albumin levels in the presence of inflammation are likely associated with the effects of inflammatory cytokines including interleukin6 (IL-6) and tumor necrosis factor-alpha. Recent studies have clearly demonstrated that serum albumin levels have protective properties, such as preventing apoptosis and maintaining physiological homeostasis, antioxidant activity, and anti-inflammatory effects.?

Previous studies have also demonstrated that the fibrinogen/albumin ratio (FAR) is higher in many different diseases including hypertension, atherosclerosis, cardiovasculary diseases, myocardial infarction, contrast induced nephropathy, ankylosing

Disclosure. Authors have no conflict of interests, and the work was not supported or funded by any drug company. spondylitis, and various cancers, which is related to inflammatory conditions in the body. ${ }^{10-14}$ The FAR is an inflammatory-based prognostic index which offers information on disease severity, prognosis or patient survival. ${ }^{11-14}$ Based on these observations, the purpose of present study was to investigate the alteration of FAR in pregnant women with $\mathrm{AI}$ and its prognostic value for predicting spontaneous abortion.

Methods. A prospective observational study was conducted in Research and Training Hospital, Balikesir University, Balikesir, Turkey between September 2019 and August 2020. The investigation protocol of the study was in accordance with the Helsinki committee requirement. The study protocol was approved by Balikesir University Institutional Ethical Committee (Date: 28/08/2019, No: 2019/111). Pregnant women who have vaginal bleeding and the ages and body mass indexes (BMIs) matched controls were participated in the study population. All subjects gave written informed consent. A total of 102 pregnant women, 52 of AI, 50 of age and BMI matched healthy control were included in the study population during the first antenatal visit. The loss of pregnancy before the 20 weeks of gestation was defined as spontaneous abortion. All pregnancies without spontaneous abortion followed until 20th week of gestation. The demographic characteristic, ultrasonography measurements, and laboratory parameters were obtained prospectively from all participants and their electronic records. Pregnant women who had fetal anomaly, recurrent pregnancy loss, intrauterine infections, serious systemic diseases, multiple pregnancies, and in vitro fertilization were excluded. All participants were non smokers, in the same socioeconomic status and non-obese $\left(<30 \mathrm{~kg} / \mathrm{m}^{2}\right)$. In addition, all participants did not use vitamin and mineral supplementation other than folic acid.

Obstetric and physical examinations of all participants were performed in our antenatal outpatient clinics. The demographic characteristics such as maternal age, BMI, and previous obstetric and medical histories were recorded in the first prenatal visit. The gestational weeks were determined according to biometric measurement (croved-rumb-length) which performed with an ultrasound machine (GE, Voluson 730 expert, CA, USA) equipped with a transvaginal probe.

A $5 \mathrm{ml}$ antecubital venous blood samples were obtained at the time of diagnosis in the AI group and routine antenatal visit in the control group. Blood samples were divided into the 2 and approximately half of them put into light blue tube buffered sodium 
citrate $0.109 \mathrm{M}(3.2 \%)$ for the fibrinogen $(\mathrm{mg} / \mathrm{dL})$ measurement and remaining half of the put into gold tube including clot activator and gel for serum separation for the measurement albumin levels $(\mathrm{g} / \mathrm{dL})$. All collected sample were centrifugate at $4000 \mathrm{rpm}$ for 10 minutes and were storage in deep freeze at $-80^{\circ} \mathrm{C}$ until analysis.

Abortus imminens was defined as presence of any degree of vaginal bleeding confirmed with vaginal speculum examination and close internal and external cervical ostium confirmed with transvaginal ultrasound. During the followed period, there was no detected maternal comorbities, fetal anomaly, and coagulation abnormality in all of AI and control pregnancies. Pregnant women with AI were prescribe with $200 \mathrm{mg}$ natural micronized progesterone orally or intravaginally twice a day to eliminate the risk of progesterone insufficiency following collection of blood samples.

Biochemical evaluation. Blood levels of fibrinogen were measured using the fibrinogen clotting time on Clauss method as described elsewhere. ${ }^{15}$ In this method, plasma samples was dilued 1/10 and thrombin solution was added, the clotting time of samples was recorded and plasma fibrinogen concentrations of all samples were calculated using standard charts. Plasma fibrinogen levels was considered normal ranges at 200-400 mg/dL. ${ }^{7}$ Serum levels of albumin were measured via a bromocresol green dye-binding analyzer (Roche Modular DP, Roche Diagnostics, Basel, Switzerland). Serum albumin level was considered normal range at 3.2-5.5 g/dL. FAR was calculated by dividing the plasma fibrinogen concentration by the serum albumin concentration. To avoid assay variability, all collected blood samples were analyzed together. Complete blood counts of participants were measured via a blood count analyser (Sysmex XE-2100, Kobe, Japan).

A power analysis was performed by using the data of previous studies that provide information of fibrinogen levels in pregnancy ${ }^{16}$ and necessary sample size in $\mathrm{AI}$ and control group were found as 46 of AI and 46 controls in ratio of $1: 1$ when the desired significance level was set at 0.05 (alpha) and power was set at 0.8 (1-Beta). Therefore, it was calculated that 46 control patients were required for at least 46 patients in the AI group in order to test whether there was a significant difference in the FAR levels between AI and the control group.

Statistical analysis. All statistical analysis was made using MedCalc Statistical Software version 19.2.1 (MedCalc Software Ltd, Ostend, Belgium; https:// www.medcalc.org; 2020). The Kolmogrov-Smirnov test was used for the evaluation the distribution of variables in the groups. Levene test or F test was used for the evaluation of the variances between the groups. All variables was evaluate by describing the mean \pm standard deviation (SD) or median (min-max), where applicable. The student's t-test and Mann-Whitney test were applied for comparisons for independent measurements of mean or median values. The Chi-square test was used to evaluate he differences between categorical data. The univariate logistic regression was used to evaluate associated factors that effect FAR value. For the purpose determining the cut-off value of FAR, the receiver operating characteristic (ROC) analysis was used. Data were evaluated in the $95 \%$ confidence interval (CI). One-way analysis of variance (ANOVA) test was used to compare the independent groups more than 2. A $p$-value less than 0.05 were considered statistically significant.

Results. A total of 102 pregnant women, 52 with AI and 50 healthy controls, participated in the study population. The mean age of pregnant women was 30.1 \pm 5.8 in the AI group and $29.6 \pm 6.1$ in the control group. The mean BMI of pregnant women was $23.2 \pm 2.5$ in the AI group, and 23.6 \pm 2.9 in the control group. There was no statistically significant difference in terms of age and BMI between the groups ( $p=0.6743$ and $p=0.4667$, respectively). Demographic variables of participants were summarized in Table 1.

The spontaneous abortion rate was 14/52 (26.9\%) in AI group and 0/50 (0\%) in control group. Compared the control pregnancies, the rate of spontaneous abortion rate was significantly higher in AI group $(p=0.0001)$. Also in the AI group, 15/52 (28.8\%) experienced pelvic pain and 21/52 (40.4\%) experienced abdominal cramps and there was a statistical significant differences between in pregnancies with AI $(p<0.0001)$ and controls $(p<0.0001)$.

Regarding the alteration of inflammatory parameters in pregnancies with and without AI, plasma fibrinogen concentration were significantly higher, and serum albumin concentration significantly lower, in AI pregnancies compared to the controls ( $p=0.0374$ and $p=0.0150$, respectively). As expected, calculated FAR values were significantly higher in AI pregnancies than in the control group ( $p=0.0088$ ) (Table 2). Our subgroup analysis demonstrated that plasma fibrinogen (Figure 2), and FAR levels (Figure 4) were significantly higher and serum albumin levels (Figure 3) was significantly lower in AI pregnancies with spontaneous abortion than in AI pregnancies without spontaneous abortion and control pregnancies $(p=0.001, p=0.002$, and $p<0.001$, respectively). 
Table 1 - Demographic characteristic of abortus imminens (AI) and control patients.

\begin{tabular}{|c|c|c|c|}
\hline Characteristics & AI group $(n=52)$ & Control group $(n=50)$ & $P$-value \\
\hline Age (year), mean $\pm S D($ min-max $)$ & $30.1 \pm 5.8(20-41)$ & $29.6 \pm 6.1(21-41)$ & $0.6743^{*}$ \\
\hline BMI $\left(\mathrm{kg} / \mathrm{m}^{2}\right)$, mean $\pm \mathrm{SD}(\min -\max )$ & $23.2 \pm 2.5(19.2-28.9)$ & $23.6 \pm 2.9(18.5-29.3)$ & $0.4667^{*}$ \\
\hline Gestational Age (weeks), mean $\pm S D$ & $9.1 \pm 1.5$ & $8.3 \pm 1.5$ & $0.1404^{*}$ \\
\hline Gravidity $(\mathrm{n})$, mean \pm SD & $2.2 \pm 1.1$ & $2.3 \pm 1.1$ & $0.7554^{*}$ \\
\hline Parity $(\mathrm{n})$, mean $\pm S D$ & $0.6 \pm 0.9$ & $0.7 \pm 0.8$ & $0.7038^{*}$ \\
\hline Systolic blood pressure $(\mathrm{mmHg})$, mean $\pm \mathrm{SD}$ & $109.4 \pm 13.6$ & $107.6 \pm 10.9$ & $0.4585^{*}$ \\
\hline Diastolic blood pressure $(\mathrm{mmHg})$, mean $\pm \mathrm{SD}$ & $71.9 \pm 7.7$ & $70.6 \pm 7.5$ & $0.3821^{*}$ \\
\hline Plasma glucose levels (mg/dL), mean $\pm S D$ & $79.1 \pm 7.2$ & $77.9 \pm 8.4$ & $0.4562^{*}$ \\
\hline \multicolumn{4}{|l|}{ Type of vaginal bleeding ( $n$ ) } \\
\hline Spotting & 19 & & \\
\hline Pink & 8 & & \\
\hline Red & 17 & - & - \\
\hline Like a menstruation & 8 & & \\
\hline \multicolumn{4}{|l|}{ Presence of pelvic pain (n) } \\
\hline Yes & 15 & 0 & \multirow{2}{*}{$<0.0001$} \\
\hline No & 37 & 50 & \\
\hline \multicolumn{4}{|l|}{ Presence of abdominal cramp ( $n$ ) } \\
\hline Yes & 21 & 0 & \multirow{2}{*}{$<0.0001^{\dagger}$} \\
\hline No & 31 & 50 & \\
\hline \multicolumn{4}{|l|}{ Spontanous abortion (n) } \\
\hline Yes & 14 & 0 & \multirow{2}{*}{$0.0001^{\dagger}$} \\
\hline No & 38 & 50 & \\
\hline
\end{tabular}

Table 2 - Inflammatory parameters of patients with and without abortus imminens (AI).

\begin{tabular}{lccc}
\hline Parameters & AI group $(\mathbf{n}=52)$ & Control group $(\mathbf{n}=50)$ & $P$-value* \\
\hline White blood cell count & $9217.3 \pm 1955.9$ & $9040.0 \pm 1607.5$ & 0.6188 \\
Neutrophil count & $6284.6 \pm 1963.9$ & $6214.1 \pm 2089.6$ & 0.8609 \\
Lymphocytes count & $2155.8 \pm 573.1$ & $2126.1 \pm 421.3$ & 0.7664 \\
Fibrinogen level & $369.1 \pm 72.2$ & $339.8 \pm 67.7$ & 0.0374 \\
Albumin level & $3.73 \pm 0.36$ & $3.92 \pm 0.42$ & 0.0150 \\
Fibrinogen to albumin ratio & $100.5 \pm 24.6$ & $88.1 \pm 22.1$ & 0.0088 \\
\hline
\end{tabular}

Values are presented as mean \pm standard diviation. ${ }^{*}$ Student $t$-test, SD: standard deviation

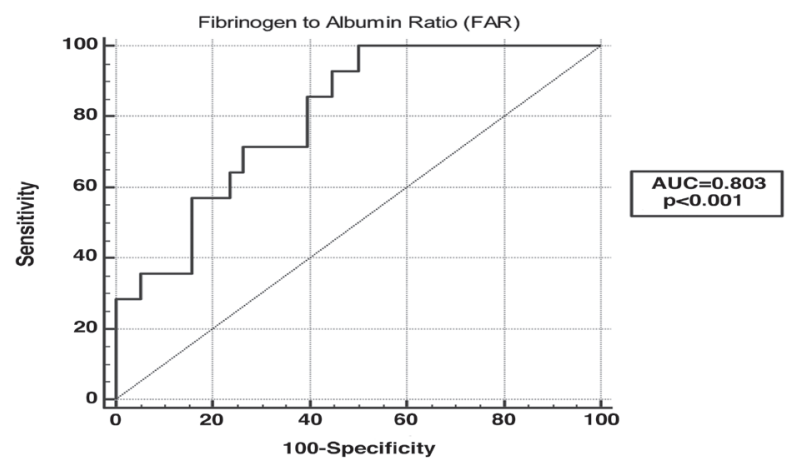

Figure 1 - The receiver operating characteristic analysis was performed to investigate the effect of FAR value in predicting spontaneous abortion in pregnancies with abortus imminens; FAR: Fibrinogen to albumin ratio. The area under the ROC curve of FAR was $0.803(p<0.001)$.

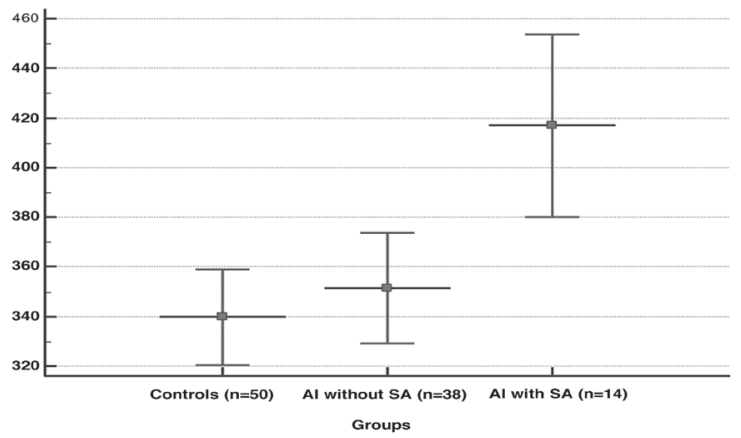

Figure 2 - Plasma levels of fibrinogen in the groups (data show a mean $\pm S D$ ). Subgroup analysis demonstrated that plasma fibrinogen concentration was significantly higher in abortus imminens (AI) with spontaneous abortion (SA) than AI without SA and controls ( $p=0.001$, ANOVA test). 
A univariate logistic regression analysis demonstrated that only BMI was a possible confounding factor affecting FAR values (odds ratio [OR]: 2.9615 [95\% CI: 1.2633 to 6.9425]; $p=0.0111$ ) (Table 3). Identification of independent risk factors for the development of spontaneous abortion in the AI group, both a univariate and multivariate logistic regression model were performed (Table 4). A univariate logistic regression analysis have shown that the BMI (odds ratio [OR]: 4.4286 [95\% CI: 1.1706 to 16.7536]; $p=0.0274$ ), type of vaginal bleeding (OR: 6.4815 [95\% CI: 1.2982 to 32.3588]; $p=0.0201$ ) and the FAR values (OR: 9.2000 [95\% CI: 1.7986 to 47.0589]; $p=0.0020$ ) were associated risk factors for the development of spontaneous abortion. In the multivariate logistic regression model, only the FAR values (OR: 7.3116

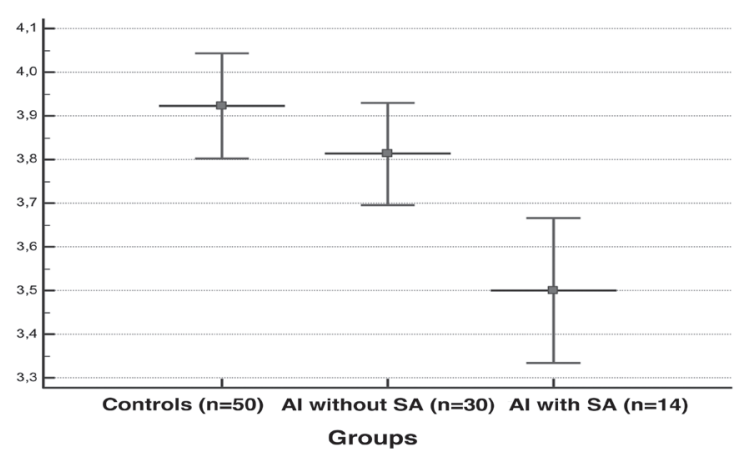

Figure 3 - Plasma levels of fibrinogen in the groups (data show a mean $\pm S D$ ). Subgroup analysis demonstrated that plasma fibrinogen concentration was significantly higher in abortus imminens (AI) with spontaneous abortion (SA) than AI without SA and controls ( $p=0.001$, ANOVA test).

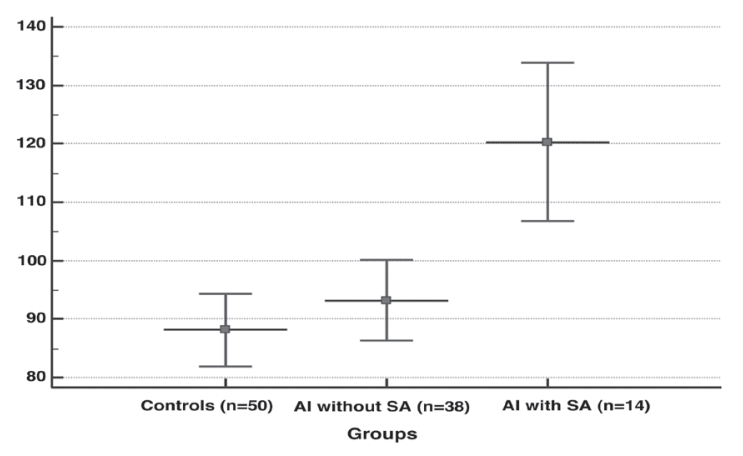

Figure 4 - Fibrinogen/albumin ratio (FAR) in the groups (Data show a mean $\pm S D$ ). Subgroup analysis demonstrated that FAR levels were significantly higher in abortus imminens (AI) with spontaneous abortion (SA) than AI without SA and controls $(p<0.001$, ANOVA test)
[95\% CI: 1.3119 to 40.7507]; $p=0.0232$ ) was found to be an independent marker for the prediction of spontaneous abortion in AI.

The ROC analysis have shown that the area under the ROC curve for FAR was 0.803 (95\% CI: 0.669-0.900; $p<0.0001)$. Youden's index established cut-off values of $>97.18$ for FAR (sensitivity $=85.7 \%$; specificity $=60.5 \%$ ).

Discussion. In this study, we evaluate the alteration of FAR in AI pregnancies and its prognostic value in predicting spontaneous abortion. According to our present results, pregnant women with AI demonstrated significantly higher levels of FAR in blood samples as compared to women without AI. Moreover, a univariate and multivariate logistic regression analyses clearly demonstrated that increased levels of FAR was an independent risk factor for the development of spontaneous abortion in this pregnancy group.

Vaginal spotting or bleeding in early pregnancy is a common complication, and it may be associated with the development of spontaneous abortion. In the extant literature on the subject, the spontaneous abortion rate has been reported as $14-50 \%$ in AI pregnancies: ${ }^{17,18}$ in the present study population, the rate was $26.9 \%$. Several maternal and fetal etiopathogenetic factors are associated with the development of spontaneous abortion in AI pregnancies, such as genetic disorders, increased maternal age and BMI, previous spontaneous abortion history, abnormal placental development, infectious diseases, and immunolosgical factors. ${ }^{19}$ However, regardless of underlying etiological factors, vaginal bleeding is an early indicator of placental dysfunction and progression to abortion in some $\mathrm{AI}$ cases. ${ }^{3}$ In these instances, placental dysfunction and altered perfusion may eventually lead to placental ischemia and oxidative stress. A recent study conducted by Jauniaux et $\mathrm{al}^{20}$ have shown that the blood flow alteration in intervillous vessels usually occurs much earlier in the abortion group than in normal pregnancies. The authors concluded that in miscarriage group, there was a close relationship between altered placental blood flow and oxidative damage in placental tissue. Under these conditions, oxidative stress activates vascular endothelial cells and systemic inflammatory responses, which is the main cause for the development of pregnancy complications, including spontaneous abortion. ${ }^{3,5}$ Comparable to these results, previous studies have clearly demonstrated that there was a close relationship between higher levels of inflammatory makers and development of threatened abortion and early pregnancy loss. ${ }^{21,22}$ 
Table 3 - Possible confounding factors associated with fibrinogen/albumin ratio values.

\begin{tabular}{|c|c|c|c|c|}
\hline \multirow{2}{*}{ Variables } & \multicolumn{4}{|c|}{ Univariate logistic regression analysis } \\
\hline & $\mathbf{n}$ & OR & $95 \% \mathrm{CI}$ & $P$-value \\
\hline \multicolumn{5}{|l|}{ Age (year) } \\
\hline$<30$ & 49 & 1.0 & 1.0 (references) & \multirow{2}{*}{0.5183} \\
\hline$\geq 30$ & 53 & 1.2946 & 0.5908 to 2.8369 & \\
\hline \multicolumn{5}{|l|}{ Body mass index $\left(\mathrm{kg} / \mathrm{m}^{2}\right)$} \\
\hline$<25$ & 68 & 1.0 & 1.0 (references) & \multirow{2}{*}{0.0111} \\
\hline$\geq 25$ & 34 & 2.9615 & 1.2633 to 6.9425 & \\
\hline \multicolumn{5}{|l|}{ Gestational ages (weeks) } \\
\hline$<9$ & 58 & 1.0 & 1.0 (references) & \multirow[b]{2}{*}{0.5226} \\
\hline$\geq 9$ & 44 & 1.2935 & 0.5874 to 2.8481 & \\
\hline \multicolumn{5}{|l|}{ Gravidity (n) } \\
\hline$<2$ & 37 & 1.0 & 1.0 (references) & \multirow{2}{*}{0.3336} \\
\hline$\geq 2$ & 65 & 1.4979 & 0.6573 to 3.4133 & \\
\hline \multicolumn{5}{|l|}{ Parity (n) } \\
\hline$<1$ & 60 & 1.0 & 1.0 (references) & \multirow{2}{*}{0.7067} \\
\hline$\geq 1$ & 42 & 1.1311 & 0.5941 to 2.1534 & \\
\hline \multicolumn{5}{|l|}{ Systolic blood pressure } \\
\hline$<110$ & 44 & 1.0 & 1.0 (references) & \multirow{2}{*}{0.8301} \\
\hline$\geq 110$ & 58 & 1.0909 & 0.4926 to 2.4160 & \\
\hline \multicolumn{5}{|l|}{ Diastolic blood pressure } \\
\hline$<80$ & 62 & 1.0 & 1.0 (references) & \multirow{2}{*}{0.7915} \\
\hline$\geq 80$ & 40 & 0.8975 & 0.4025 to 2.0014 & \\
\hline \multicolumn{5}{|l|}{ Type of vaginal bleeding } \\
\hline Spotting, pink or red & 44 & 1.0 & 1.0 (references) & \multirow{2}{*}{0.1466} \\
\hline Like a menstruation & 8 & 3.2857 & 0.5966 to 18.0972 & \\
\hline \multicolumn{5}{|l|}{ Presence of pelvic pain (n) } \\
\hline No & 37 & 1.0 & 1.0 (references) & \multirow{2}{*}{0.1720} \\
\hline Yes & 15 & 2.3529 & 0.6720 to 8.2390 & \\
\hline \multicolumn{5}{|c|}{ Presence of abdominal cramp ( $n$ ) } \\
\hline No & 31 & 1.0 & 1.0 (references) & \multirow{2}{*}{0.0777} \\
\hline Yes & 21 & 2.7692 & 0.8732 to 8.7824 & \\
\hline
\end{tabular}

In the literature, a number of studies have shown that plasma levels of FAR are significantly higher in many diseases such as hypertension, atherosclerosis, cardiovasculary diseases, myocardial infarction, ankylosing spondylitis and various cancer, which is related to inflammatory conditions in the body. ${ }^{10-14}$ Karahan et $\mathrm{al}^{13}$ clearly demonstrated that FAR may predict the severity of coronary artery atherosclerosis in patients with myocardial infarction. Similarly, Ozdemir et $\mathrm{a}^{10}$ have demonstrated that plasma FAR levels were higher in patients with hypertension than in controls.

Comparable to these results, the FAR has been shown to be a good prognostic indicator for patients with breast cancer. ${ }^{14}$ In a recent research conducted by Tan et $\mathrm{al}^{11}$ indicated that increased plasma FAR value was an independent risk factor for poor prognosis, early recurrence and short cancer-free survival times in patients with esophageal squamous cell carcinoma. Lui et $\mathrm{al}^{12}$ have also shown that plasma FAR values were higher in ankylosing spondylitis than in controls; therefore, they concluded that the FAR may be a novel inflammatory parameter for monitoring activity of the diseases in patients with ankylosing spondylitis. Thus, it may be argued that the FAR can serve as an inflammatory based prognostic indicator in many diseases that cause systemic inflammation. ${ }^{11,12,14}$

Regarding the role of fibrinogen or albumine levels in the normal and abnormal pathophysiological conditions in human pregnancies, there were a small number of studies that investigated and results were vary. Manten et $\mathrm{al}^{23}$ indicated that compared to normal pregnancies, circulating levels of total fibrinogen and particularly high molecular weight fibrinogen concentration were slightly increased in pre-eclampsia. 
Table 4 - A univariate and multivariate logistic regression analysis showing the predictors for the development of spontaneous abortion in pregnancies with abortus imminens.

\begin{tabular}{|c|c|c|c|c|c|c|c|}
\hline \multirow{2}{*}{ Variables } & \multirow[b]{2}{*}{$\mathrm{n}$} & \multicolumn{3}{|c|}{ Univariate logistic regression analysis } & \multicolumn{3}{|c|}{ Multivariate logistic regression analysis } \\
\hline & & OR & $95 \% \mathrm{CI}$ & $P$-value & OR & $95 \% \mathrm{CI}$ & $P$-value \\
\hline \multicolumn{8}{|l|}{ Age (year) } \\
\hline$<30$ & $5 / 24$ & 1.0 & 1.0 (references) & & & & \\
\hline$\geq 30$ & $9 / 28$ & 1.8000 & 0.5082 to 6.3758 & 0.3563 & & & \\
\hline \multicolumn{8}{|l|}{ Body mass index $\left(\mathrm{kg} / \mathrm{m}^{2}\right)$} \\
\hline$<25$ & $7 / 38$ & 1.0 & 1.0 (references) & & & & \\
\hline$\geq 25$ & $7 / 14$ & 4.4286 & 1.1706 to 16.7536 & 0.0274 & 2.8925 & 0.6471 to 12.9296 & 0.1644 \\
\hline \multicolumn{8}{|l|}{ Gestational ages (weeks) } \\
\hline$<9$ & $7 / 25$ & 1.0 & 1.0 (references) & & & & \\
\hline$\geq 9$ & $7 / 27$ & 0.9000 & 0.2641 to 3.0668 & 0.8662 & & & \\
\hline \multicolumn{8}{|l|}{ Gravida (n) } \\
\hline$<2$ & $4 / 18$ & 1.0 & 1.0 (references) & & & & \\
\hline$\geq 2$ & $10 / 34$ & 1.4583 & 0.3842 to 5.5350 & 0.5743 & & & \\
\hline \multicolumn{8}{|l|}{ Parite (n) } \\
\hline$<1$ & $9 / 32$ & 1.0 & 1.0 (references) & & & & \\
\hline$\geq 1$ & $5 / 20$ & 0.8519 & 0.2387 to 3.0398 & 0.8042 & & & \\
\hline \multicolumn{8}{|l|}{ Fibrinogen/albumin ratio } \\
\hline$<97.2$ & $2 / 25$ & 1.0 & 1.0 (references) & & & & \\
\hline$\geq 97.2$ & $12 / 27$ & 9.2000 & 1.7986 to 47.0589 & 0.0020 & 7.3116 & 1.3119 to 40.7507 & 0.0232 \\
\hline \multicolumn{8}{|l|}{ Type of vaginal bleeding } \\
\hline Spotting, pink or red & $9 / 44$ & 1.0 & 1.0 (references) & & & & \\
\hline Like a menstruation & $5 / 8$ & 6.4815 & 1.2982 to 32.3588 & 0.0201 & 4.4784 & 0.7440 to 26.9560 & 0.1016 \\
\hline \multicolumn{8}{|c|}{ Presence of abdominal cramp ( $n$ ) } \\
\hline No & $6 / 31$ & 1.0 & 1.0 (references) & & & & \\
\hline Yes & $8 / 21$ & 2.5641 & 0.7325 to 8.9752 & 0.1374 & & & \\
\hline \multicolumn{8}{|l|}{ Presence of pelvic pain (n) } \\
\hline No & $9 / 38$ & 1.0 & 1.0 (references) & & & & \\
\hline Yes & $6 / 14$ & 2.4167 & 0.6612 to 8.8326 & 0.1852 & & & \\
\hline
\end{tabular}

Therefore, the authors concluded that increased levels of total fibrinogen concentration and alteration of high molecular weight fibrinogen may play a role in vasculary endothelial activation, and exaggerated inflammatory response which are believed to be underlying molecular mechanisms in pre-eclampsia. ${ }^{23}$ Similarly, Davitson et $\mathrm{al}^{24}$ demonstrated that pregnacies with hypertension have higher fibrinogen concentrations in blood samples compared to controls. Tetik et $\mathrm{a}^{25}$ also showed that circulating fibrinogen concentration were significantly higher in IUGR than control pregnancies. However, Chen et $\mathrm{al}^{26}$ asserted that compared to non-pregnant women and healthy pregnancies, women with preeclampsia have lower fibrinogen levels in the third trimester. These conflicting results may be associated with differences in sample sizes, demographic characteristics of participants or fibrinogen to fibrin transformation on the third trimester. It is known that circulating levels of fibrinogen immediately decrease in parallel with the amount of acute hemorrhage during the abortion and postpartum hemorrhage.

According to the extant literature, serum albumin levels, unlike fibrinogen, decreases in the presence of pregnancy related hypertension, and it is a useful predictor for timing of delivery, presence of severe proteinuria, and poor prognosis of pregnancy. ${ }^{27}$ Ozdemir et $\mathrm{al}^{28}$ indicated that serum albumin levels in first trimester were significantly lower in women with histories of recurrent pregnancy loss than in controls. Comparably, we found that serum albumin concentration was significantly decreased in the AI group than in the controls.

The present study also determined that vaginal bleeding in early pregnancy was associated with 
increased fibrinogen levels and decreased albumin levels in blood samples. Also, the FAR was significantly higher in pregnant women with AI than in controls and increased FAR values in women with AI was an independent risk factor for subsequent spontaneous abortion.

In normal pregnancy, there is a mild systemic inflammatory response which is promote with the progression of pregnancy and peaks during the third trimester. This physiological inflammatory response is characterized by slightly increase in the circulating concentration of cytokines, as well as the activation of white blood cells such as neutrophils, lymphocytes, monocytes, and granulocytes. ${ }^{29}$ However, in pregnancies with miscarriage or threatened abortion, the intensity of the systemic inflammatory response is stronger than normal pregnancies due to the increase of proinflammatory cytokines in the maternal circulation. ${ }^{30}$ In the present study, contrary to FAR leves, there were no differences in white blood cell, neutrophil and lymphocytes counts between in pregnancies with and without AI. These results may be associated with small number of study population, mild systemic inflammation among the participants, and the participants' early gestational age. However, it may also be that the FAR is a more sensitive inflammatory marker than other indicators.

On the other hand, in the literature there was a few studies have evaluated the relation between the presence of abdominal cramp, pelvic pain and type of vaginal bleeding with the development of the spontaneous abortion. ${ }^{21,22}$ Those authors have found a close relationship between increased inflammatory status and uterine contractions with progressive cervical effacement and dilatation, which can initiate and maintain labor at any gestational age. ${ }^{21,22}$ The present study determined that pelvic pains or abdominal cramps were significantly higher in AI pregnancies than in control pregnancies. However, we did not find any association between presence of pelvic pain, abdominal cramp or type of vaginal bleeding with progression to spontaneous abortion.

Study limitations. There was no any information on patients' physical examinations and laboratory parameters was available. There was a progesterone exposure in the AI group (but not in the control group). There was no information on the genetic consequences of abortion materials in pregnancies with spontaneous abortion. The authors also had no information on maternal and perinatal pregnancy complications after 20 weeks of gestation or their association with the FAR.
In conclusion, the present results have shown that AI pregnancies exhibit increased FAR values compared to healthy pregnancies. FAR levels were associated with progression to spontaneous abortion. These higher FAR levels and their association with spontaneous abortion may be related to the underlying molecular mechanism of AI.

Acknowledgment. We would like to thank all staff of the Department of Obstetrics and Gynecology, School of Medicine, Balikesir University for their assistance in data collection step. We also would like to thank Scribendi (www.scribendi.com) for English language editing.

\section{References}

1. Simpson JL, Mills JL, Holmes LB, Ober CL, Aarons J, Jovanovic $\mathrm{L}$, et al. Low fetal loss rates after ultrasound-proved viability in early pregnancy. JAMA 1987; 258: 2555-2557.

2. Weiss JL, Malone FD, Vidaver J, Ball RH, Nyberg DA, Comstock $\mathrm{CH}$, et al. Threatened abortion: a risk factor for poor pregnancy outcome, a population-based screening study. Am J Obstet Gynecol 2004; 190: 745-750.

3. Katar-Yildirim C, Tokmak A, Yildirim C, Erel O, Caglar AT. Investigation of serum thiol/disulphide homeostasis in patients with abortus imminens. J Matern Fetal Neonatal Med 2018 Sep 17; 31: 2457-2462.

4. Kaufmann P, Black S, Huppertz B. Endovascular Trophoblast Invasion: Implications for the Pathogenesis of Intrauterine Growth Retardation and Preeclampsia. Biol Reprod 2003; 69: 1-7.

5. Gupta S, Agarwal A, Banerjee J, Alvarez JG. The role of oxidative stress in spontaneous abortion and recurrent pregnancy loss: a systematic review. Obstet Gynecol Surv 2007; 62: 335-347.

6. Ghanim B, Hoda MA, Klikovits T, Winter M-P, Alimohammadi A, Grusch M, et al. Circulating fibrinogen is a prognostic and predictive biomarker in malignant pleural mesothelioma. $\mathrm{Br} J$ Cancer 2014; 110: 984-990.

7. Sadeghi M, Akhlaghi L, Rahimi-Esboei B, Tabatabaie F. Evaluation of the Plasma Level of Fibrinogen in the First Trimester in Mothers with Toxoplasmosis. J Arch Mil Med 2018; 6: e67012.

8. Haefliger DN, Moskaitis JE, Schoenberg DR, Wahli W. Amphibian albumins as members of the albumin, alphafetoprotein, vitamin D-binding protein multigene family. J Mol Evol 1989; 29: 344-354.

9. Seo MH, Choa M, You JS, Lee HS, Hong JH, Park YS, et al. Hypoalbuminemia, low base excess values, and tachypnea predict 28-day mortality in severe sepsis and septic shock patients in the emergency department. Yonsei Med J 2016; 57 : 1361-1369.

10. Özdemir M, Yurtdaş M, Asoğlu R, Yildirim T, Aladağ N, Asoğlu E. Fibrinogen to albumin ratio as a powerful predictor of the exaggerated morning blood pressure surge in newly diagnosed treatment-naive hypertensive patients. Clin Exp Hypertens 2020; 42: 692-699.

11. Tan Z, Zhang M, Han Q, Wen J, Luo K, Lin P, et al. A novel blood tool of cancer prognosis in esophageal squamous cell carcinoma: the Fibrinogen/Albumin ratio. J Cancer 2017; 8: 1025-1029. 
12. Liu M, Huang Y, Huang Z, Zhong Z, Deng W, Huang Z, et al. The role of fibrinogen to albumin ratio in ankylosing spondylitis: Correlation with disease activity. Clin Chim Acta 2020; 505: 136-140.

13. Karahan O, Acet H, Ertaş F, Tezcan O, Çalişkan A, Demir M, et al. The relationship between fibrinogen to albumin ratio and severity of coronary artery disease in patients with STEMI. Am J Emerg Med 2016; 34:1037-1042.

14. Hwang K-T, Chung JK, Roh EY, Kim J, Oh S, Kim YA, et al. Prognostic influence of preoperative fibrinogen to albumin ratio for breast cancer. J Breast Cancer 2017; 20: 254-63.

15. Besselaar AMHP van den, Rijn CJJ van, Cobbaert CM, Reijnierse GLA, Hollestelle MJ, Niessen RWLM, et al. Fibrinogen determination according to Clauss: commutability assessment of International and commercial standards and quality control samples. Clin Chem Lab Med CCLM 2017; 55 : 1761-1769.

16. van Rijn BB, Veerbeek JH, Scholtens LC, Uiterweer EDP, Koster MP, Peeters LL, et al. C-reactive protein and fibrinogen levels as determinants of recurrent preeclampsia: a prospective cohort study. J Hypertens 2014; 32: 408-414.

17. Hasan R, Baird DD, Herring AH, Olshan AF, Jonsson Funk ML, Hartmann KE. Association between first-trimester vaginal bleeding and miscarriage. Obstet Gynecol 2009; 114: 860-867.

18. Basama FMS, Crosfill F. The outcome of pregnancies in 182 women with threatened miscarriage. Arch Gynecol Obstet 2004; 270: 86-90.

19. du Fossé NA, van der Hoorn M-LP, van Lith JMM, le Cessie S, Lashley EELO. Advanced paternal age is associated with an increased risk of spontaneous miscarriage: a systematic review and meta-analysis. Hum Reprod Update 2020; 26: 650-669.

20. Jauniaux E, Gulbis B, Burton GJ. The human first trimester gestational sac limits rather than facilitates oxygen transfer to the foetus-a review. Placenta 2003; 24: S86-S93.
21. Ata N, Kulhan M, Kulhan NG, Turkler C. Can neutrophillymphocyte and platelet-lymphocyte ratios predict threatened abortion and early pregnancy loss? Ginekol Pol 2020; 91 : 210-215.

22. Bas FY, Tola EN, Sak S, Cankaya BA. The role of complete blood inflammation markers in the prediction of spontaneous abortion. Pak J Med Sci 201834: 1381.

23. Manten GTR, Sikkema JM, Franx A, Hameeteman TM, Visser GHA, de Groot PG, et al. Increased high molecular weight fibrinogen in pre-eclampsia. Thromb Res 2003; 111: 143-147.

24. Davidson EC, Phillips LL. Coagulation studies in the hypertensive toxemias of pregnancy. Am J Obstet Gynecol 1972; 113: 905-910.

25. Tetik K, Seçkin KD, Karslı FM, Sarıaslan S, Çakmak B, Danıșman N. Can we use as a marker the maternal serum levels of D-dimer and fibrinogen to predict intra uterin growth restriction? Turk J Obstet Gynecol 2014; 11: 228.

26. Chen Y, Lin L. Potential value of coagulation parameters for suggesting preeclampsia during the third trimester of pregnancy. Am J Med Sci 2017; 354: 39-43.

27. Seong WJ, Chong GO, Hong DG, Lee TH, Lee YS, Cho $\mathrm{YL}$, et al. Clinical significance of serum albumin level in pregnancy-related hypertension. J Obstet Gynaecol Res 2010; 36: $1165-173$.

28. Özdemir S, Kıyıcı A, Balci O, Göktepe H, Çiçekler H, Çelik Ç. Assessment of ischemia-modified albumin level in patients with recurrent pregnancy loss during the first trimester. Eur J Obstet Gynecol Reprod Biol 2011; 155: 209-212.

29. MacLean MA, Wilson R, Thomson JA, Krishnamurthy S, Walker JJ. Changes in immunologic parameters in normal pregnancy and spontaneous abortion. Am J Obstet Gynecol 1991; 165: 890-895.

30. Paradisi R, Porcu E, Venturoli S, Maldini冈Casadei M, Boni P. Maternal serum levels of pro- inflammatory cytokines in missed and threatened abortion. Am J Reprod Immunol 2003; 50: 302-308 